\title{
Fast Fault Section Estimation in Distribution Substations Using Matrix-Based Cause-Effect Networks
}

\author{
Wen-Hui Chen, Chih-Wen Liu, and Men-Shen Tsai
}

\begin{abstract}
A new method for estimating fault sections in power substations is proposed. In this paper, the knowledge representation and inference procedures based on the cause-effect networks (CE-Nets) and rule matrix transformation techniques are presented. The matrix based inference procedures are proposed to estimate the possible fault sections through simple matrix operations by transforming the established CE-Nets into matrix forms. The method is superior to existing production systems in the inference speed and the process of implementation. By testing on a typical Taiwan Power Company's (Taipower) secondary substation, the experimental results show that the effectiveness of the proposed method even for the fault domains involving multiple faults and failure operations of protective devices. Moreover, it is easy to implement and transplant into different substations.
\end{abstract}

Index Terms-Cause-effect network, fault diagnosis, rule matrix.

\section{INTRODUCTION}

W ITH recent advances in computer and communication technologies, the computer-based Supervisory Control And Data Acquisition (SCADA) systems are increasingly used in the modern electric utility field. The ultimate goal for a power system is to supply a reliable and stable power to the customs. However, it is inevitable that disturbances such as lightning strokes, collisions and equipment failures will occur. In case of a fault does occur, it is imperative to restrict the impact of outages to the minimum and to restore the faulted facilities as quickly as possible. This requires the location and nature of the fault first be identified, which is the main issue of fault diagnosis in power systems. Taiwan Power Company (TPC) has implemented a Hierarchical Dispatch and Control System (HDCS) to meet the requirements of Taiwan's highly industrialized society in a better quality and higher reliability fashion. The HDCS is a three-level control system, which comprises a CDCS (Central Dispatch and Control System), six ADCSs (Area Dispatch and Control System) and nineteen DDCSs (Distribution Dispatch and Control System). In a DDCS control center, on average, the operator is responsible for more than fifteen unmanned secondary substations simultaneously. In normal operating conditions, operators can properly

Manuscript received May 15, 2000.

W.-H. Chen and C.-W. Liu are with the Department of Electrical Engineering, National Taiwan University, Taipei, Taiwan.

M.-S. Tsai is with the Department of Electrical Engineering, Chinese Culture University, Taipei, Taiwan.

Publisher Item Identifier S 0885-8977(01)07075-3. deal with various situations. Once faults appear, the operators may find it difficult to analyze the faults and take appropriate actions in the overwhelming alarm messages. This task become increasingly complex if multiple faults have occurred or some pieces of equipment have malfunctioned. Our research was motivated by the result of discussing with the operators in Keelung DDCS located in northern Taiwan. An opinion was expressed that a fault diagnosis tool ought to be developed as an operator's aid function in control center.

In recent decades, a number of technical papers with different methods [1]-[8], such as Expert Systems (ES) and Artificial Neural Networks (ANN) have been successfully applied for power system fault diagnosis. However, there are still some weak points to be improved in conventional methods. For example, the inference speed of rule-based ES is slow in real-time environments due to its sequentially searches for the solution by pattern matching to the hypotheses. As to the ANN techniques, some problems still remain unsolved in practical application so far, such as slow convergence in the training process, and the determination of the network parameters. Besides, neither the cause nor the algorithm for the diagnosis could be determined by the ANN. In [9], the knowledge representations and inference procedures using CE-Nets and marker propagation were presented. However, the conventional inference algorithm has no solution in some situations.

In this paper, a matrix-based inference mechanism is proposed to overcome the aforementioned drawback and provide a better way to the implementation issue. This paper focuses on fault diagnosis for automated substations and assumes that the information on the status of relays and circuit breakers is available from SCADA systems subjected to the following problem domains:

1) Single fault without failure device.

2) Single fault with more than one failure device.

3) Multiple faults without failure device.

4) Multiple faults with more than one failure device.

A section of the substation here refers as a feeder, a bus bar or a transformer, which can be separated by breakers. Prior to dealing with such a fault diagnosis problem, the following assumptions are also given:

1) The action of relays is caused by the fault.

2) All relays and circuit breakers are in their final states.

3) Operations of any devices are known through SCADA systems and updated in the database. 


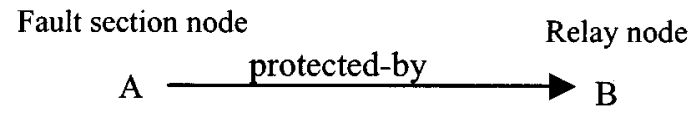

(a)

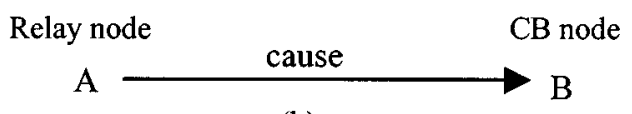

(b)

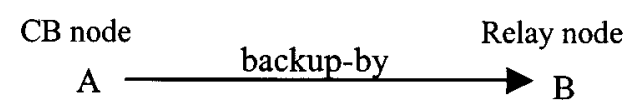

(c)

Fig. 1. (a) Protected-by arc. (b) Cause arc. (c) Backup-by arc.

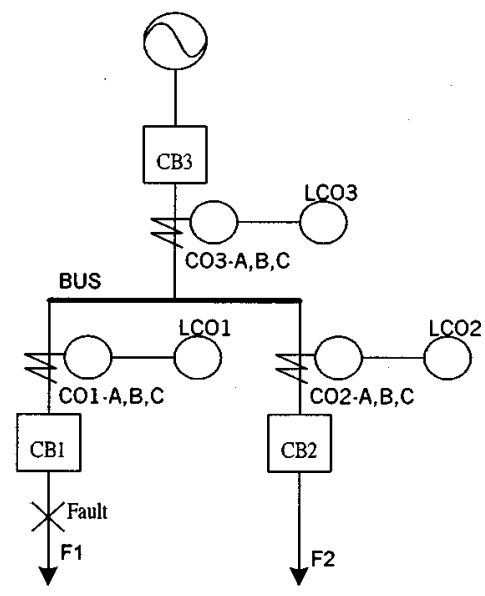

Fig. 2. A simple model distribution system.

\section{CAUSE-EFFECT NeTWORK}

A CE-Net is a graphic-modeling tool for representing the causality between faults and actions of protective devices, including the three kinds of nodes below:

1) Fault section node

This node represents a section hit by a fault.

2) Relay node

This node indicates the action of a protective relay.

3) $C B$ node

This node means the action of a circuit breaker.

In addition, there are three kinds of arcs as shown in Fig. 1.

1) Protected-by

Means that a fault in section A causes the action of relay $B$.

2) Cause

Means that the action of relay A causes the trip of circuit breaker B.

3) Backup-by

Means that the failure of circuit breaker A causes the action of relay $\mathrm{B}$.

A simple model distribution system, as shown in Fig. 2, is used to illustrate the knowledge representation by the CE-Nets. The model system is protected by Over Current (CO) relays, Low-energy Over Current (LCO) relays and Circuit Breakers (CB). Suppose that a fault occurs at F1, it causes the action of relay $\mathrm{CO} 1$, which trips the circuit breaker $\mathrm{CB} 1$. As $\mathrm{CB} 1$ fail to

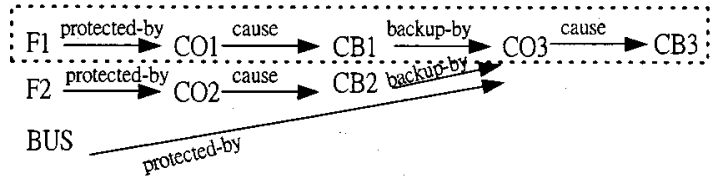

Fig. 3. CE-Nets of model system.

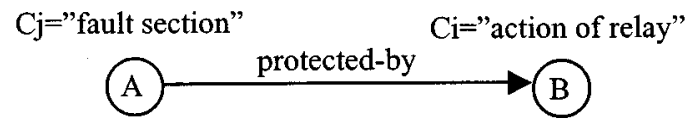

(a)

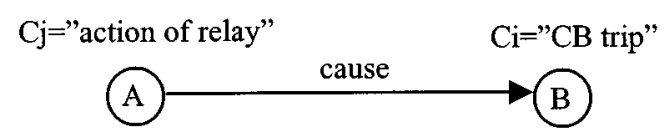

(b)

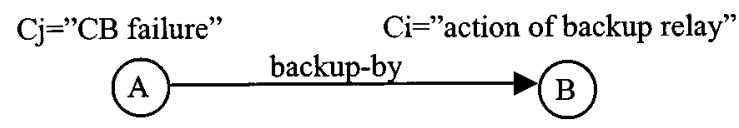

(c)

Fig. 4. (a) Relation of protected-by arc. (b) Relation of cause arc. (c) Relation of backup-by arc.

open at this time, the backup protective relay $\mathrm{CO} 3$ will actuate to trip circuit breaker CB3. This event is shown by the portion of dashed line in Fig. 3. After considering all the possible faulted sections, we can get the CE-Nets of the model system as shown in Fig. 3.

\section{MATRIX REPRESENTATION OF CE-NETS}

Once the CE-Nets are established, the next step of the proposed method is to transform them to the rule matrix. Suppose that $C i$ and $C j$ are conditions of nodes in given CE-Nets, a rule matrix $R$ with entry $R(i, j)=1$ means that the truth of condition $C j$ implies the truth of condition $C i$. On the other hand, $R(i, j)=0$ indicates that there is no implication between $C i$ and $C j$. The diagonal of $R$ contains all ones by reflexivity and with Boolean entries ( 0 or 1$)$ through three relations as shown in Fig. 4.

To explain matrix representation of the CE-Nets, Fig. 5 is used for illustration.

By observing the connection of each nodes, the rule matrix of Fig. 5 can therefore be constructed as

$\begin{gathered}C 1 \\ \mathbf{R}\end{gathered}=\left[\begin{array}{lllllllllll|l}\mathbf{1} & \mathbf{0} & \mathbf{0} & \mathbf{0} & \mathbf{0} & \mathbf{0} & \mathbf{0} & \mathbf{0} & \mathbf{0} & \mathbf{0} & \mathbf{0} \\ \mathbf{1} & \mathbf{1} & \mathbf{0} & \mathbf{0} & \mathbf{0} & \mathbf{0} & \mathbf{0} & \mathbf{0} & \mathbf{0} & \mathbf{0} & \mathbf{0} & C 1 \\ \mathbf{0} & \mathbf{1} & \mathbf{1} & \mathbf{0} & \mathbf{0} & \mathbf{0} & \mathbf{0} & \mathbf{0} & \mathbf{0} & \mathbf{0} & \mathbf{0} & C 3 \\ \mathbf{0} & \mathbf{0} & \mathbf{0} & \mathbf{1} & \mathbf{0} & \mathbf{0} & \mathbf{0} & \mathbf{0} & \mathbf{0} & \mathbf{0} & \mathbf{0} & C 4 \\ \mathbf{0} & \mathbf{0} & \mathbf{0} & \mathbf{1} & \mathbf{1} & \mathbf{0} & \mathbf{0} & \mathbf{0} & \mathbf{0} & \mathbf{1} & \mathbf{1} & C 5 \\ \mathbf{0} & \mathbf{0} & \mathbf{0} & \mathbf{0} & \mathbf{1} & \mathbf{1} & \mathbf{0} & \mathbf{0} & \mathbf{0} & \mathbf{0} & \mathbf{0} & C 6 \\ \mathbf{0} & \mathbf{0} & \mathbf{0} & \mathbf{0} & \mathbf{0} & \mathbf{0} & \mathbf{1} & \mathbf{0} & \mathbf{0} & \mathbf{0} & \mathbf{0} & C 7 \\ \mathbf{0} & \mathbf{0} & \mathbf{0} & \mathbf{0} & \mathbf{0} & \mathbf{0} & \mathbf{1} & \mathbf{1} & \mathbf{0} & \mathbf{0} & \mathbf{0} & C 8 \\ \mathbf{0} & \mathbf{0} & \mathbf{0} & \mathbf{0} & \mathbf{0} & \mathbf{0} & \mathbf{0} & \mathbf{1} & \mathbf{1} & \mathbf{0} & \mathbf{0} & C 9 \\ \mathbf{0} & \mathbf{0} & \mathbf{0} & \mathbf{0} & \mathbf{0} & \mathbf{0} & \mathbf{0} & \mathbf{0} & \mathbf{0} & \mathbf{1} & \mathbf{0} & C 10 \\ \mathbf{0} & \mathbf{0} & \mathbf{0} & \mathbf{0} & \mathbf{0} & \mathbf{0} & \mathbf{0} & \mathbf{0} & \mathbf{0} & \mathbf{0} & \mathbf{1}\end{array}\right] \begin{gathered}C 11 \\ \end{gathered}$




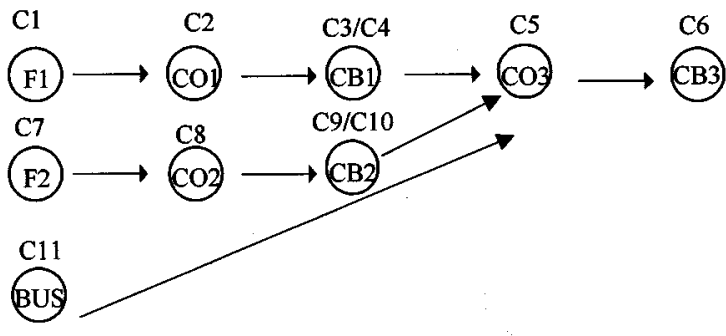

Fig. 5. CE-Nets for illustration of matrix representation.

The set of conditions is listed below:

C1) Fault occurs at F1 section

C2) Relay CO1 actuated

C3) Circuit Breaker CB1 tripped

C4) $\mathrm{CO} 1$ actuated, but $\mathrm{CB} 1$ failed (i.e., $C 2 \wedge \overline{\mathrm{C} 3}$ )

C5) Relay $\mathrm{CO} 3$ actuated

C6) Circuit Breaker CB3 tripped

C7) Fault occurs at F2 section

C8) Relay $\mathrm{CO} 2$ actuated

C9) Circuit Breaker CB2 tripped

C10) $\mathrm{CO} 2$ actuated, but $\mathrm{CB} 2$ failed (i.e., $C 8 \wedge \overline{C 9}$ )

C11) Fault occurs at BUS section.

\section{INFERENCE PROCEDURES}

Prior to developing the inference procedures, we define the following column vectors for matrix operations.

Truth state vector $(T)$

$$
T(i)= \begin{cases}1, & \text { if } C i \text { is true } \\ 0, & \text { otherwise }\end{cases}
$$

where $C i$ is a condition of nodes in given CE-Nets. Fault node vector $(F)$

$$
F(i)= \begin{cases}1, & \text { if } C i \in \text { fault section node } \\ 0, & \text { otherwise }\end{cases}
$$

Backup condition vector $(B)$

$B(i)= \begin{cases}1, & \text { if } C i \in \mathrm{CB} \text { node of backup-by } \\ 0, & \text { otherwise }\end{cases}$

Transformation Vector (TV)

$$
\mathrm{TV} \equiv R^{T} \oplus T
$$

where " $\oplus$ " is the multiplication of two matrices, which replace real multiplication and addition with AND and OR, respectively. The operation process called truth state transformation.

For example,

$$
\begin{aligned}
& {\left[\begin{array}{ll}
1 & 1 \\
0 & 1
\end{array}\right] \oplus\left[\begin{array}{l}
0 \\
1
\end{array}\right]} \\
& =\left[\begin{array}{lllllll}
(1 & \text { AND } & 0) & \text { OR } & (1 & \text { AND } & 1
\end{array}\right)=\left[\begin{array}{l}
1 \\
1
\end{array}\right]
\end{aligned}
$$

Fault Section Vector (FSV)

$$
\mathrm{FSV}=(\mathrm{TV}-T) \odot F
$$

where " $\odot$ " is the AND operation of two column vectors.

For example,

$$
\left[\begin{array}{l}
0 \\
0 \\
1
\end{array}\right] \odot\left[\begin{array}{l}
1 \\
0 \\
1
\end{array}\right]=\left[\begin{array}{lll}
0 & \text { AND } & 1 \\
0 & \text { AND } & 0 \\
1 & \text { AND } & 1
\end{array}\right]=\left[\begin{array}{l}
0 \\
0 \\
1
\end{array}\right]
$$

Elimination vector $(E)$

$$
E \equiv T \odot B
$$

The transpose of a rule matrix corresponds to the reversal of all arrows in the associated CE-Nets and takes a truth state of given results backward into an abduced state of cause [10]. Since the truth state transformation preserves truth states and propagates truths, the transformation vector (TV) contains the information of all possible causes. In order to pick up a possible fault section, we define the fault section vector (FSV) to get rid of the result states and filter the state of nonfault section nodes. If the elimination vector $(E)$ is not a zero vector, it means that there must be a backup relay actuated. In such situation, the main protective section of backup relays should be eliminated from fault section candidates. The proposed inference procedures are achieved through the following steps:

Steps of Inference:

Step 1) Establishing rule matrix, $R$, of given CE-Nets.

Step 2) Deriving truth state vector, $T$, from fault information.

Step 3) Calculating transformation vector, TV.

Step 4) Calculating fault section vector, FSV.

Step 5) Selecting fault section candidates from entries comprising " 1 " of FSV.

Step 6) Calculating elimination vector, $E$. If $E$ is a zero vector, the fault section candidates selected from step 5 are chosen as the fault sections. On the other hand, if $E$ is not a zero vector, the main protective section of the backup relay that corresponding to nonzero entries of $E$ should be eliminated from fault section candidates and the rest of candidates are chosen as the fault sections.

\section{EXAMPLES}

We use a realistic Taipower's secondary substation to demonstrate the proposed method. Two case studies of the example substation are presented without loss of generality.

The substation is composed of three sub-transmission lines, three main transformers, two tie circuit breakers, one $69 \mathrm{KV}$ primary bus bar and three $11.4 \mathrm{KV}$ secondary bus bars. Each secondary bus contains five radial distribution feeders which are protected by $\mathrm{CO}$ relays, $\mathrm{LCO}$ relays and reclosers. The main transformers are protected by differential relays. The bus bars are protected by CO and LCO relays and as the back-up protection for each feeder. The three-phase, four-wire distribution 


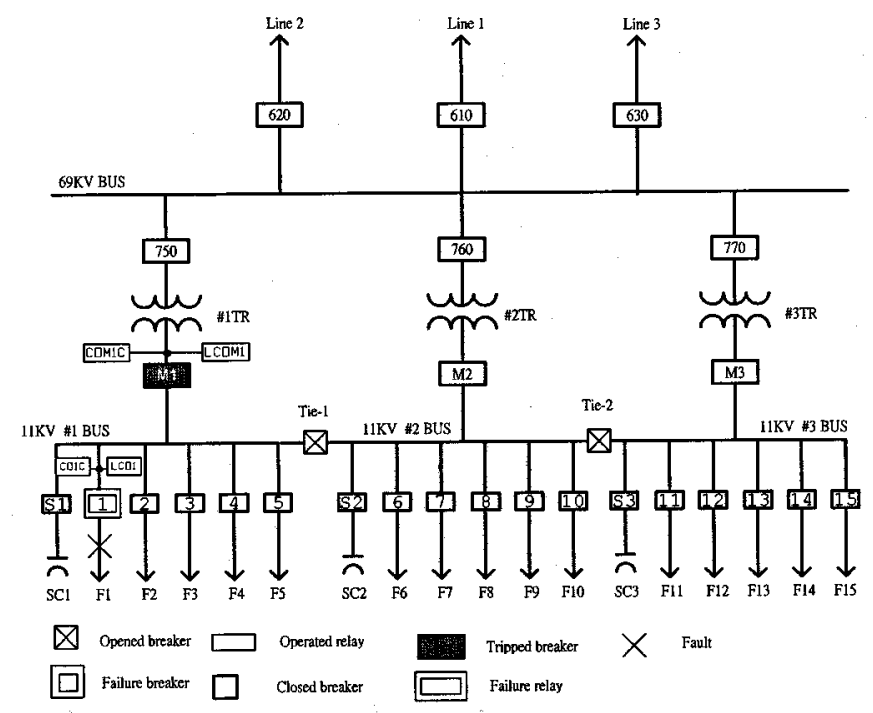

Fig. 6. Fault situation of case 1.

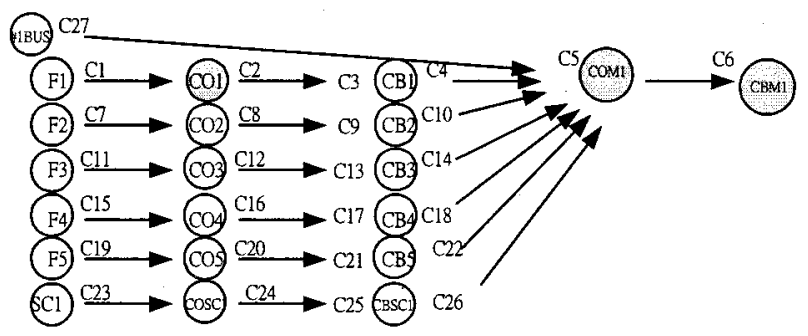

Fig. 7. The associated CE-Nets of case 1.

system is solidly grounded at substation, with the neutral wire also grounded at each distribution transformer location.

Case 1 (Single Fault with One Failure Device):

Operated relays: CO1-C, LCO1, COM1- $C$, and LCOM1

Tripped circuit breaker: CBM1

Failure device: CB1

This is a case that a single line-to-ground fault occurs at phase $C$ of feeder section F1 in Fig. 6. The main protective relays "CO1-C" and LCO1 operate. However, the associate breaker, $\mathrm{CB} 1$, fails to trip. Owing to the tripping failure of $\mathrm{CB} 1$, backup circuit breaker CBM1 is tripped by COM1-C and LCOM1.

At first, we perform a logic-OR operation into each phase relays of the same feeder (e.g., CO1-A, CO1-B, CO1-C) and the related grounded relay (LCO1) to be an aggregated relay (CO1), i.e., $\mathrm{CO} 1$ operated if CO1-A or CO1-B or CO1-C or LCO1 operated. In this manner, we can get the desired aggregated CE-Nets [11]. The portion of the CE-Nets, which is associated with this event, is given in Fig. 7. The set of conditions is listed below:

C1) Fault occurs at F1 section

C2) Relay CO1 actuated

C3) Circuit Breaker CB1 tripped

C4) $\mathrm{CO} 1$ actuated, but $\mathrm{CB} 1$ failed (i.e., $C 2 \wedge \overline{C 3}$ )

C5) Relay COM1 actuated

C6) Circuit Breaker CBM1 tripped

C7) Fault occurs at F2 section

C8) Relay $\mathrm{CO} 2$ actuated

C9) Circuit Breaker CB2 tripped
C10) $\mathrm{CO} 2$ actuated, but $\mathrm{CB} 2$ failed (i.e., $C 8 \wedge \overline{C 9}$ )

C11) Fault occurs at F3 section

C12) Relay $\mathrm{CO} 3$ actuated

C13) Circuit Breaker CB3 tripped

C14) $\mathrm{CO} 3$ actuated, but $\mathrm{CB} 3$ failed (i.e., $C 12 \wedge \overline{C 13}$ )

C15) Fault occurs at F4 section

C16) Relay CO4 actuated

C17) Circuit Breaker CB4 tripped

C18) $\mathrm{CO} 4$ actuated, but $\mathrm{CB} 4$ failed (i.e., $C 16 \wedge \overline{C 17}$ )

C19) Fault occurs at F5 section

C20) Relay CO5 actuated

C21) Circuit Breaker CB5 tripped

C22) $\mathrm{CO} 5$ actuated, but $\mathrm{CB} 5$ failed (i.e., $C 20 \wedge \overline{C 21}$ )

C23) Fault occurs at $\mathrm{SC} 1$ section

C24) Relay COSC1 actuated

C25) Circuit Breaker CBSC1 tripped

C26) COSC1 actuated, but CBSC1 failed (i.e., $C 24 \wedge \overline{C 25}$ )

C27) Fault occurs at \#1 BUS section

Step 1: The rule matrix of the associated CE-Net could be found as shown at the bottom of the page.

Step 2: Since CO1, COM1 and CBM1 have actuated, the truth state vector $(T)$ of this case can be derived as follows

$$
T=[0101110000000000000000000000]^{T} \text {. }
$$

Step 3: Consequently, we can get fault section candidates of this fault situation by performing the truth state transformation. $\mathrm{TV}=R^{T} \oplus T$

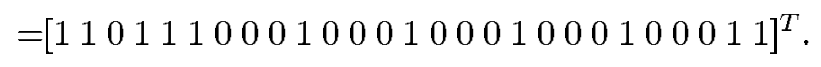

Step 4: The fault node vector $(F)$ could be derived from CE-Nets

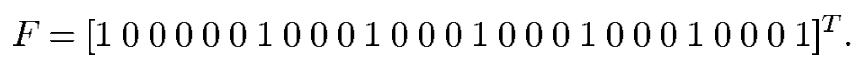

Hence, we can calculate FSV as follows

$$
\begin{aligned}
& \mathrm{FSV}=(\mathrm{TV}-T) \odot F
\end{aligned}
$$

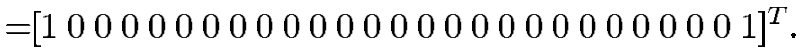

Step 5: FSV contains information of all fault section candidates in the way that contains a "1" in its component. By observing the fact that $\mathrm{FSV}(1)=\mathrm{FSV}(27)=1$, corresponding to conditions $\mathrm{C} 1$ and $\mathrm{C} 27$ hold, we select F1 and \#1 BUS as the fault section candidates.

Step 6: By checking elimination vector $(E)$

$$
\begin{aligned}
& E=T \odot B
\end{aligned}
$$

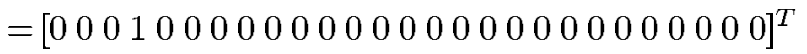

where

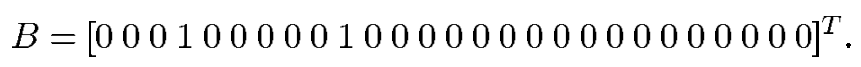

Obviously, $E$ is not a zero vector. Hence, the candidate \#1 BUS is eliminated from fault section candidates due to $E(4)=1$. Finally, we can easily get the cause of the fault stemmed from section F1 hit by a fault.

Case 2 (Multiple Faults with More Than One Failure Devices):

Operated relays: CO3-A, CO3-B, CO3-C, COM1-A, COM1-B, COM1-C and CO8-B, CO8-C

Tripped circuit breakers: CBM1, CB8

Failure devices: LCO8, CB3. 


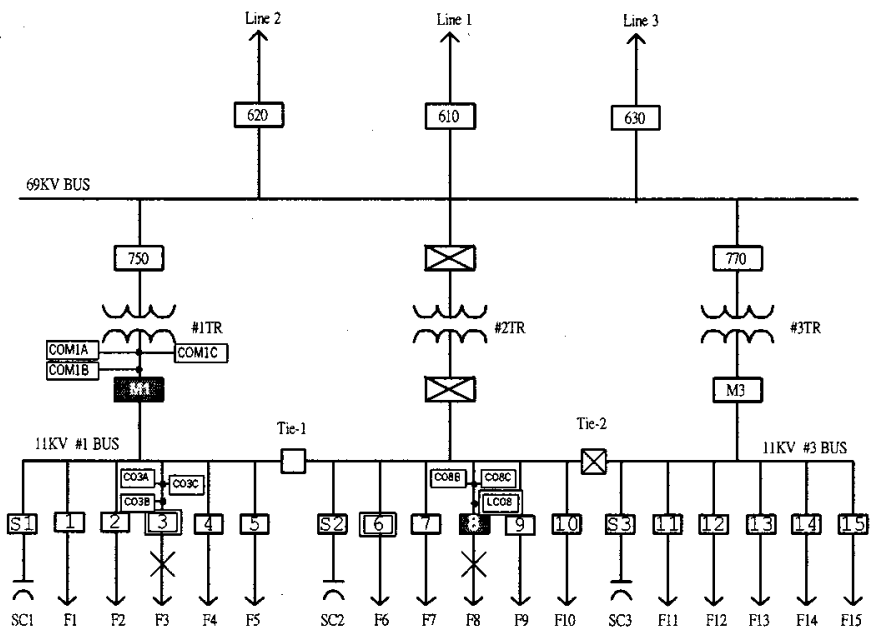

Fig. 8. Fault situation of case 2 .

In this case, \#2 TR has de-energized for maintenance and Tie-1 breaker is in the closing status. A three-phase fault occurs at F3. Relays "CO3-A," "CO3-B" and "CO3-C" operate correctly while breaker "CB3" has failed to trip. Owing to the tripping failure of "CB3," the backup breaker "CBM1" is tripped by the operation of relays "COM1-A," "COM1-B"

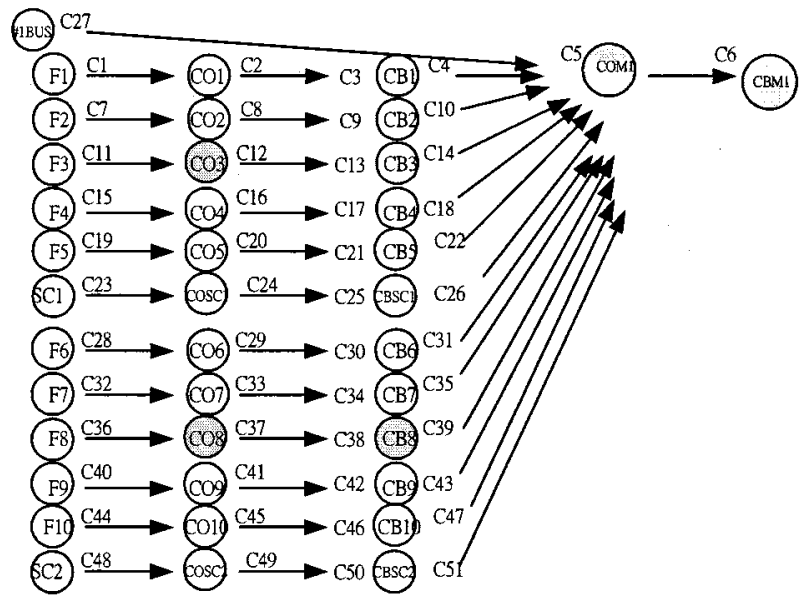

Fig. 9. The associated CE-Nets of case 2.

and "COM1-C." Meanwhile, a double-line to ground fault at phases $\mathrm{B}$ and $\mathrm{C}$ has happened at $\mathrm{F} 8$, which causes "CO8-B" and "CO8-C" operate to trip "CB8," but "LCO8" fails. The fault situation is shown in Fig. 8.

The associated CE-Nets of this event are shown in Fig. 9. The results of the inference are listed in Table I. From Table I, we

$$
\begin{aligned}
& \begin{array}{lllllllllllllllllllllllllll}
1 & 2 & 3 & 4 & 5 & 6 & 7 & 8 & 9 & 10 & 1 & 2 & 3 & 4 & 5 & 6 & 7 & 8 & 9 & 20 & 1 & 2 & 3 & 4 & 5 & 6 & 7
\end{array} \\
& 1\left[\begin{array}{lllllllllllllllllllllllllll}
1 & 0 & 0 & 0 & 0 & 0 & 0 & 0 & 0 & 0 & 0 & 0 & 0 & 0 & 0 & 0 & 0 & 0 & 0 & 0 & 0 & 0 & 0 & 0 & 0 & 0 & 0 \\
1 & 1 & 0 & 0 & 0 & 0 & 0 & 0 & 0 & 0 & 0 & 0 & 0 & 0 & 0 & 0 & 0 & 0 & 0 & 0 & 0 & 0 & 0 & 0 & 0 & 0 & 0 \\
0 & 1 & 1 & 0 & 0 & 0 & 0 & 0 & 0 & 0 & 0 & 0 & 0 & 0 & 0 & 0 & 0 & 0 & 0 & 0 & 0 & 0 & 0 & 0 & 0 & 0
\end{array}\right] \\
& \begin{array}{llllllllllllllllllllllllllll}
2 & 1 & 1 & 0 & 0 & 0 & 0 & 0 & 0 & 0 & 0 & 0 & 0 & 0 & 0 & 0 & 0 & 0 & 0 & 0 & 0 & 0 & 0 & 0 & 0 & 0 & 0 & 0 \\
3 & 0 & 1 & 1 & 0 & 0 & 0 & 0 & 0 & 0 & 0 & 0 & 0 & 0 & 0 & 0 & 0 & 0 & 0 & 0 & 0 & 0 & 0 & 0 & 0 & 0 & 0 & 0
\end{array} \\
& 4 \begin{array}{llllllllllllllllllllllllllll}
4 & 0 & 0 & 1 & 0 & 0 & 0 & 0 & 0 & 0 & 0 & 0 & 0 & 0 & 0 & 0 & 0 & 0 & 0 & 0 & 0 & 0 & 0 & 0 & 0 & 0 & 0
\end{array} \\
& 5 \quad 0 \begin{array}{lllllllllllllllllllllllllll}
5 & 0 & 0 & 1 & 1 & 0 & 0 & 0 & 0 & 1 & 0 & 0 & 0 & 1 & 0 & 0 & 0 & 1 & 0 & 0 & 0 & 1 & 0 & 0 & 0 & 1 & 1
\end{array} \\
& 6 \quad 0 \begin{array}{lllllllllllllllllllllllllll}
6 & 0 & 0 & 0 & 1 & 1 & 0 & 0 & 0 & 0 & 0 & 0 & 0 & 0 & 0 & 0 & 0 & 0 & 0 & 0 & 0 & 0 & 0 & 0 & 0 & 0 & 0
\end{array} \\
& 7 \quad 0 \begin{array}{lllllllllllllllllllllllllll} 
& 0 & 0 & 0 & 0 & 0 & 1 & 0 & 0 & 0 & 0 & 0 & 0 & 0 & 0 & 0 & 0 & 0 & 0 & 0 & 0 & 0 & 0 & 0 & 0 & 0 & 0
\end{array} \\
& 8 \quad 0 \begin{array}{lllllllllllllllllllllllllll}
8 & 0 & 0 & 0 & 0 & 0 & 1 & 1 & 0 & 0 & 0 & 0 & 0 & 0 & 0 & 0 & 0 & 0 & 0 & 0 & 0 & 0 & 0 & 0 & 0 & 0 & 0
\end{array} \\
& 9 \begin{array}{llllllllllllllllllllllllllll}
9 & 0 & 0 & 0 & 0 & 0 & 0 & 1 & 1 & 0 & 0 & 0 & 0 & 0 & 0 & 0 & 0 & 0 & 0 & 0 & 0 & 0 & 0 & 0 & 0 & 0 & 0
\end{array} \\
& 10 \begin{array}{llllllllllllllllllllllllllll} 
& 0 & 0 & 0 & 0 & 0 & 0 & 0 & 0 & 0 & 1 & 0 & 0 & 0 & 0 & 0 & 0 & 0 & 0 & 0 & 0 & 0 & 0 & 0 & 0 & 0 & 0 & 0
\end{array}
\end{aligned}
$$

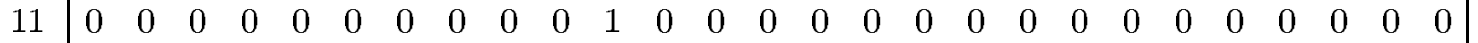

$$
\begin{aligned}
& 12100 \begin{array}{lllllllllllllllllllllllllll} 
& 0 & 0 & 0 & 0 & 0 & 0 & 0 & 0 & 0 & 1 & 1 & 0 & 0 & 0 & 0 & 0 & 0 & 0 & 0 & 0 & 0 & 0 & 0 & 0 & 0 & 0
\end{array} \\
& \mathbf{R}=\begin{array}{llllllllllllllllllllllllllll}
13 & 0 & 0 & 0 & 0 & 0 & 0 & 0 & 0 & 0 & 0 & 0 & 1 & 1 & 0 & 0 & 0 & 0 & 0 & 0 & 0 & 0 & 0 & 0 & 0 & 0 & 0 & 0 \\
14 & 0 & 0 & 0 & 0 & 0 & 0 & 0 & 0 & 0 & 0 & 0 & 0 & 0 & 1 & 0 & 0 & 0 & 0 & 0 & 0 & 0 & 0 & 0 & 0 & 0 & 0 & 0
\end{array} \\
& 15 \quad \begin{array}{lllllllllllllllllllllllllll}
0 & 0 & 0 & 0 & 0 & 0 & 0 & 0 & 0 & 0 & 0 & 0 & 0 & 0 & 1 & 0 & 0 & 0 & 0 & 0 & 0 & 0 & 0 & 0 & 0 & 0 & 0
\end{array} \\
& 16 \quad \begin{array}{llllllllllllllllllllllllllll} 
& 0 & 0 & 0 & 0 & 0 & 0 & 0 & 0 & 0 & 0 & 0 & 0 & 0 & 0 & 1 & 1 & 0 & 0 & 0 & 0 & 0 & 0 & 0 & 0 & 0 & 0 & 0
\end{array} \\
& 17 \quad \begin{array}{llllllllllllllllllllllllllll} 
& 0 & 0 & 0 & 0 & 0 & 0 & 0 & 0 & 0 & 0 & 0 & 0 & 0 & 0 & 0 & 1 & 1 & 0 & 0 & 0 & 0 & 0 & 0 & 0 & 0 & 0 & 0
\end{array} \\
& 18 \quad 0 \begin{array}{lllllllllllllllllllllllllll} 
& 0 & 0 & 0 & 0 & 0 & 0 & 0 & 0 & 0 & 0 & 0 & 0 & 0 & 0 & 0 & 0 & 1 & 0 & 0 & 0 & 0 & 0 & 0 & 0 & 0 & 0
\end{array}
\end{aligned}
$$

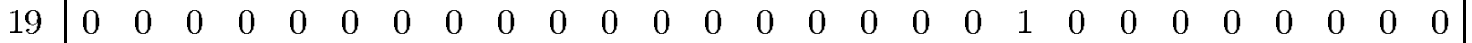

$$
\begin{aligned}
& 20 \begin{array}{llllllllllllllllllllllllllll} 
& 0 & 0 & 0 & 0 & 0 & 0 & 0 & 0 & 0 & 0 & 0 & 0 & 0 & 0 & 0 & 0 & 0 & 0 & 1 & 1 & 0 & 0 & 0 & 0 & 0 & 0 & 0
\end{array}
\end{aligned}
$$

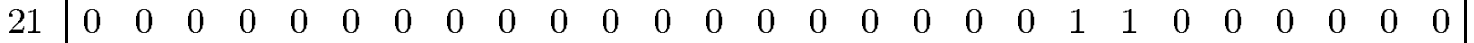

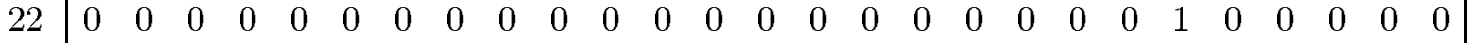

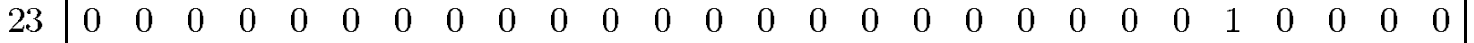

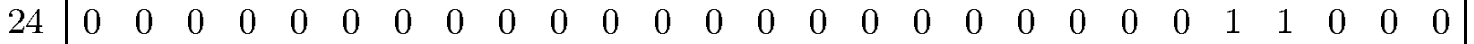

$$
\begin{aligned}
& 25 \quad 0 \begin{array}{lllllllllllllllllllllllllll} 
& 0 & 0 & 0 & 0 & 0 & 0 & 0 & 0 & 0 & 0 & 0 & 0 & 0 & 0 & 0 & 0 & 0 & 0 & 0 & 0 & 0 & 0 & 1 & 1 & 0 & 0
\end{array} \\
& 26\left[\begin{array}{lllllllllllllllllllllllllll}
0 & 0 & 0 & 0 & 0 & 0 & 0 & 0 & 0 & 0 & 0 & 0 & 0 & 0 & 0 & 0 & 0 & 0 & 0 & 0 & 0 & 0 & 0 & 0 & 0 & 1 & 0
\end{array}\right. \\
& 27\left[\begin{array}{lllllllllllllllllllllllllll}
0 & 0 & 0 & 0 & 0 & 0 & 0 & 0 & 0 & 0 & 0 & 0 & 0 & 0 & 0 & 0 & 0 & 0 & 0 & 0 & 0 & 0 & 0 & 0 & 0 & 0 & 1
\end{array}\right]
\end{aligned}
$$


TABLE I

RESULTS OF CASE 2

\begin{tabular}{l|l|c|c|c|c}
\hline $\begin{array}{c}\text { Conditions } \\
\text { hold }\end{array}$ & $\begin{array}{c}\text { Nonzero } \\
\text { entries of } \\
\text { T }\end{array}$ & $\begin{array}{c}\text { Nonzero } \\
\text { entries of } \\
\text { TV }\end{array}$ & $\begin{array}{c}\text { Nonzero } \\
\text { entries of } \\
\text { FSV }\end{array}$ & $\begin{array}{c}\text { Nonzero } \\
\text { entries of } \\
\text { E }\end{array}$ & $\begin{array}{c}\text { Fault } \\
\text { section } \\
\text { candidates }\end{array}$ \\
\hline C5,C6,C12 & $5,6,12,14$, & $4,5,6,10,11$, & $11,27,36$ & 14 & ${ }^{*} F 3$ \\
C14,C37 & 37,38 & $12,14,18,22$, & & & \#1BUS \\
C38 & & $\begin{array}{c}26,27,31,35, \\
36,37,38,39, \\
43,47,51\end{array}$ & & & ${ }^{* F}$ \\
& & \multicolumn{4}{|c}{ *: selected fault section }
\end{tabular}

can find that fault sections F3 and F8 are selected, i.e., multiple faults at F3 and F8 are estimated.

\section{CONCLUSION}

As an operator's auxiliary function, this paper has presented a novel approach for estimating fault sections in distribution substations. It is capable of dealing with fault sections for single and multiple faults, even subject to false operations of relays and/or breakers. In many power systems, the states of relays and breakers are on-line available in control center through SCADA systems. Therefore, the proposed method is of much benefit to the operators in analyzing fault situations and as a double-check of operator's decision. The proposed method has been observed to have the following features:

- Fast inference speed.

- Plainness of knowledge representation.

- Simplicity in inference procedures.

- Ease of implementation and data base maintenance.

\section{REFERENCES}

[1] C. Fukui and J. Kawakami, "An expert system for fault section estimation using information from protective relays and circuit breakers," IEEE Trans. Power Delivery, vol. 1, no. 4, pp. 83-90, Oct. 1986.

[2] Y. Y. Hsu, F. C. Lu, Y. Chien, J. P. Liu, J. T. Lin, H. S. Yu, and R. T. Kuo, "An expert system for locating distribution system faults," IEEE Trans. Power Delivery, vol. 6, no. 1, pp. 366-372, Jan. 1991.

[3] C. A. Protopapas, K. P. Psaltiras, and A. V. Machias, "An expert system for substation fault diagnosis and alarm processing," IEEE Trans. Power Delivery, vol. 6, no. 2, pp. 648-655, Apr. 1991

[4] T. K. Ma, C. C. Liu, M. S. Tsai, R. Rogers, S. L. Muchlinski, and J. Dodge, "Operational experience and maintenance of an on-line expert system for customer restoration and fault testing," IEEE Trans. Power Systems, vol. 7, no. 2, pp. 835-842, May 1992.
[5] M. Kezunovic, P. Spasojevic, C. W. Fromen, and D. R. Sevcik, "An expert system for transmission substation event analysis," IEEE Trans. Power Delivery, vol. 8, no. 4, pp. 1942-1949, Oct. 1993.

[6] K. H. Kim and J. K. Park, "Application of hierarchical neural networks to fault diagnosis of power systems," Electrical Power \& Energy Systems, vol. 15 , no. 2, pp. 65-70, 1993.

[7] H. T. Yang, W. Y. Chang, and C. L. Huang, "On-line fault diagnosis of power substation using connectionist expert system," IEEE Trans. Power Systems, vol. 10, no. 1, pp. 323-331, Feb. 1995.

[8] M. Togami, N. Abe, T. Kitahashi, and H. Ogawa, "On the application of a machine learning technique to fault diagnosis of power distribution lines," IEEE Trans. Power Delivery, vol. 10, no. 4, pp. 1927-1936, Oct. 1995.

[9] Y. Sekine, H. Okamoto, and T. Shibamoto, "Fault section estimation using cause-effect network," in Proceedings of 2nd Symposium on Expert System Application to Power Systems, Seattle, WA, U.S.A., July 1989, pp. 277-282.

[10] C. G. Looney and A. A. Alfize, "Logical controls via Boolean rule matrix transformations," IEEE Trans. Systems, Man, and Cybernetics, vol. SMC-17, no. 6, pp. 1077-1082, Nov./Dec. 1987.

[11] W. H. Chen, C. W. Liu, and M. S. Tsai, "On-line fault diagnosis of distribution substations using hybrid cause-effect network and fuzzy rule-based method," IEEE Trans. Power Delivery. Paper Number: TR3 086, to be published.

Wen-Hui Chen was born in Taiwan in 1965. He received the B.S. degree in electrical engineering from National Taiwan Institute of Technology, Taipei, and the M.S. degree in electrical engineering from National Taiwan University, Taipei, in 1991 and 1993, respectively. Since 1993, he has been employed by Taiwan Power Company. At present, he is working as a substation automation engineer and working toward his Ph.D. degree at National Taiwan University.

Chih-Wen Liu was born in Taiwan in 1964. He received the B.S. degree in electrical engineering from National Taiwan University in 1987, Ph.D. degree in electrical engineering from Cornell University in 1994. Since 1994, he has been with National Taiwan University, where he is an associate professor of electrical engineering. His research interests include application of numerical methods to power system, motor control and GPS time transfer.

Men-Shen Tsai was born in 1961 in Taiwan. In 1993, he received his Doctoral degree from the Department of Electrical Engineering, University of Washington. He is currently an associate professor at the Department of Electrical Engineering, Chinese Culture University, Taipei, Taiwan. The research areas of Dr. Tsai include applications of intelligent systems to power systems and applications of distributed systems for distribution automation. 